\title{
VENOUS THROMBOEMBOLISM AWARENESS AMONG MEDICAL STUDENTS - INTERVENTION NEEDED
}

\author{
Tomasz Urbanek ${ }^{1,2}$, Maciej Wołkowski ${ }^{3}$, Marcela Zembura3 ${ }^{3}$, Jagoda Witkowska ${ }^{3}$, \\ Eliza Wojciechowska ${ }^{3}$, Wacław Kuczmik' \\ 'Department of General Surgery, Vascular Surgery, Angiology and Phlebology, \\ Medical University of Silesia, Katowice, Poland \\ 2European Centre of Phlebology, Katowice, Poland \\ ${ }^{3}$ Student research group of Students' Scientific Society, Department of General Surgery, \\ Vascular Surgery, Angiology and Phlebology, Medical University of Silesia, Katowice
}

\begin{abstract}
Objectives: Venous thromboembolism (VTE) is one of the most common causes of death associated with cardiovascular diseases. Despite the relatively high incidence rate, awareness and access to information about VTE risk factors as well as knowledge concerning effective prevention possibilities remain limited, including among health care professionals. The aim of the study was to assess the knowledge and awareness concerning venous thromboembolism among students of the Medical University of Silesia.

Material and methods: The study was performed on a group of 400 medical students from the Medical University of Silesia in Katowice from years 3 to 6, recruiting 100 people from each of the clinical years. The study was conducted based on a survey which included 27 questions concerning knowledge of the definition of venous thromboembolism, pathogenesis, epidemiology, risk factors, symptoms and diagnostics related to this group of patients.

Results: The proper definition of venous thromboembolism was indicated by $60 \%$ of the respondents and the proper components of Virchow's triad, which underlies the pathogenesis of deep vein thrombosis, were defined by $69 \%$. The further question answers revealed that although the study programme includes venous thromboembolism, the knowledge of the students in the field of epidemiology, symptomatology and risk factors of this affliction is still limited.

Conclusions: According to the results of the study, it is advisable to take action, including educative effort, to increase the awareness of the future medical staff about problems related to VTE.
\end{abstract}

Key words: deep venous thrombosis, education, symptoms, venous thromboembolism.

\author{
ORIGINAL PAPER \\ Phlebological Review 2018; 26, 2: 29-35 \\ DOI: https://doi.org/10.5114/pr.2018.81009
}

Submitted: 27.05 .2018

Accepted: 8.08.2018

\section{INTRODUCTION}

Venous thromboembolism (VTE), which manifests itself as deep vein thrombosis (DVT) and/or pulmonary embolism (PE), still remains a significant problem of today's medicine. Despite increasing knowledge within this area, VTE is one of the most underestimated issues of $21^{\text {st }}$ century medicine. The estimated VTE incidence rate is $1-2 / 1000$ people per year in the world's population. In Poland, the estimated incidence of VTE is 5700 people annually [1].

Despite development of diagnostic methods, most cases of DVT remain unrecognized. It applies to both proximal DVT (popliteal vein, femoral vein, iliac vein and inferior vena cava), which is diagnosed only in
$50 \%$ of cases, and distal DVT, which is symptomatic and is diagnosed only in $20 \%$ of the subjects suffering from this disease [2]. The potential cause of this situation is frequent absence of the symptoms or the presence of non-specific symptoms which patients disregard and which are hard for doctors to clarify. In many cases pulmonary embolism, which is a result of migration of a thrombus from the lower limb and pelvis venous system, is the first diagnosed symptom of this disease. It is crucial because it can result in a fatal embolism of the pulmonary artery. Embolic changes in image explorations of pulmonary arteries can affect up to $50 \%$ of patients with proximal DVT [2]. 
In terms of epidemiology, knowledge about symptoms of disease, potential risk factors and ways of proper anti-thrombotic prophylaxis are crucial.

Based on different diagnostic methods in this scope, clinical effectiveness of anti-thrombotic prophylaxis in various situations is unquestioned. It is advisable to assess every patient individually regarding risk factors and efficacy of preventive procedures. VTE is a cause of in-hospital deaths which could mostly be prevented [3]. Prevalence of VTE increases during hospitalization and presence of other risk factors of this disease [4]. Among hospitalized patients, $78 \%$ of those admitted to hospitals have more than 1 VTE risk factor and $20 \%$ of them have at least 3 risk factors at once [4]. In the USA, pulmonary embolism is a cause of 200000 deaths per year [5]. In the USA and Europe VTE leads to more deaths than AIDS, breast cancer, prostate cancer and car accidents combined [6].

Venous thromboembolism is one of the most underrated diseases among both patients and medical staff because of the common lack of symptoms, non-specific symptoms and inadequate awareness of this issue [7-9]. Actions that lead to increased awareness of prevalence of this problem, its consequences, diagnostics and prevention should be carried out both in hospital and in outpatient treatment [8]. Awareness about VT's occurrence should be raised among patients as well [9].

Education about prevalence, consequences, prophylaxis possibilities and treatment of VTE is part of medical faculties' curriculum at medical universities in Poland. Future doctors' task is to acquire knowledge about the pathophysiological basis as well as proper procedures in the group of predisposed patients. In this paper an attempt has been made to assess medical students' awareness about VTE from different clinical years.

\section{MATERIAL AND METHODS}

The study was performed on a group of 400 medical students from the Medical University of Silesia in Kato-

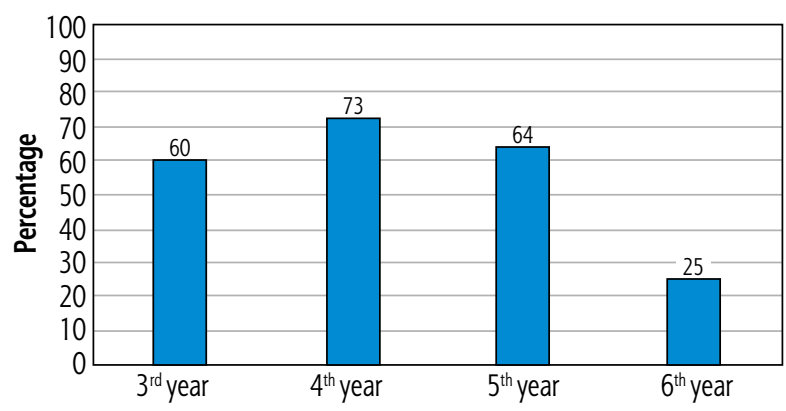

Fig. 1. Percentage of correct answers for definition of venous thromboembolism as a condition including deep vein thrombosis and/or pulmonary embolism wice from years 3 to 6 , recruiting 100 people from each of the clinical years. The study was conducted based on a survey which included 27 questions concerning knowledge of the definition of venous thromboembolism, pathogenesis and epidemiology of this affliction. In the questionnaire questions regarding risk factors, symptoms and diagnostics related to this group of patients were asked. $77 \%$ of interviewees were women and $23 \%$ were men, aged 21-28 years old. Respondents based their answers on the knowledge acquired at the university during studies.

The survey was anonymous and it was conducted between 15 October 2016 and 28 February 2017. The aim of the authors of the research tool was its clarity and preservation of an appropriate number of categorized questions, giving an opportunity to choose one answer and closed questions. Results were edited taking information about the study year of interviewees into consideration and statistically evaluated.

\section{RESULTS}

The proper definition of venous thromboembolism as an affliction manifesting as deep vein thrombosis (DVT) and/or pulmonary embolism (PE) was pointed out by $60 \%$ of interviewees and an alarmingly low rate of correct answers among 100 consecutive students of the $6^{\text {th }}$ year $(25 \%)$ (Fig. 1).

According to the majority of students $(52 \%)$ venous thromboembolism is only the $5^{\text {th }}$ cause of death due to vascular problems. The correct answer, venous thromboembolism being the $3^{\text {rd }}$ cause of death due to cardiovascular diseases (after coronary heart disease and cerebrovascular events), was given by only $50 \%$ and the most $(55 \%)$ by students of the $5^{\text {th }}$ year of studies and the least by students of the $4^{\text {th }}$ and $6^{\text {th }}$ year $-38 \%$ and $40 \%$ of correct answers respectively. Proper components of Virchow's triad, which underlies the pathogenesis of deep vein thrombosis, were defined by $69 \%$ and the best result was achieved by students of the $5^{\text {th }}$ year of studies (Fig. 2).

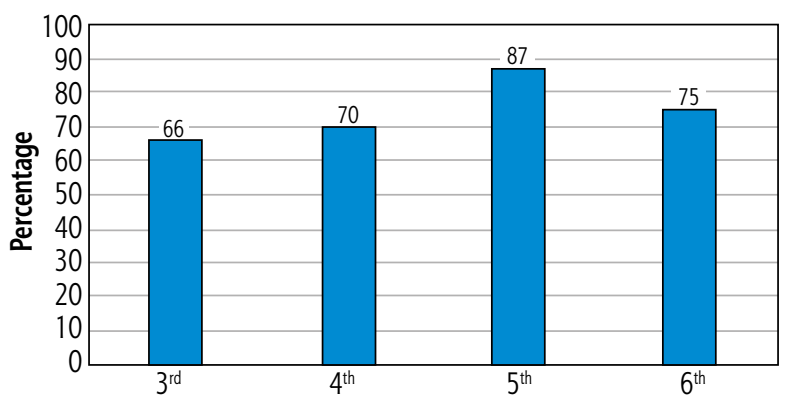

Fig. 2. Percentage of correct answers for Virchows' triad components 
Deep veins of lower limbs as the most frequent place of deep vein thrombosis and potential thrombotic material formation was indicated by $85 \%$ of respondents. Asked about the incidence of thrombosis in the population, less than half of respondents pointed out the correct answer, with a significantly higher rate of the proper answers chosen by students of the $6^{\text {th }}$ year of the university (Fig. 3).

Referring to the question about symptomatology of venous thromboembolism, $3.75 \%$ of respondents responded that venous thromboembolism is always symptomatic. $26 \%$ of students claim that in most cases pulmonary embolism is the first manifestation of venous thromboembolism (from $10 \%$ of students of the $4^{\text {th }}$ year to $40 \%$ of the $5^{\text {th }}$ year). The answer that venous thromboembolism could often be non-symptomatic and this is the reason why it is so hard to identify was chosen by $13.75 \%$ of the respondents only. The statement that deep vein thrombosis often causes pain of lower limbs and swelling, and such symptoms suggest that it may be deep vein thrombosis (so you could and should do more tests), was chosen by $52.75 \%$ of respondents (the least by students of the $4^{\text {th }}$ year, $41 \%$, and the most by students of the $6^{\text {th }}$ year, $70 \%$ ).

When we asked the students about symptoms which can occur in patients with deep venous thrombosis, swelling of the lower limbs was indicated by $6.25 \%$ of respondents (the most from the $3^{\text {rd }}$ year $-9 \%$ ), tenderness and pain was indicated by $1.75 \%$, and positive Homans' symptom was chosen by $2 \% .87 .5 \%$ of interviewees claim that all of the symptoms may suggest occurrence of deep vein thrombosis (including most of the $4^{\text {th }}$ and $6^{\text {th }}$ years).

The next question referred to the problem of specific symptoms of the venous thromboembolism $-61.25 \%$ of respondents were aware that, unfortunately, there are no specific symptoms of this disease (including most future physicians of the $6^{\text {th }}$ year $-80 \%$ ). When we asked about the possible risk factors for development of venous thromboembolism (multi-organ injury, long-term immobilization, obesity, venous thromboembolism in the interview, heart failure, stroke, cancers or all of them) the correct answer, indicating all of them, was given by only $17 \%$ of students (Fig. 4).

The twentieth question of the questionnaire was "what tests would you recommend to identify deep vein thrombosis, when there is a patient with swollen lower limbs after long-term immobilization during travel?". There were the following answers available: D-dimer assessment in urine, D-dimer assessment in serum, ultrasound compression test, ascending venography, and US duplex Doppler examination, or a combination of them. The correct answer (ultrasound compression test or duplex Doppler examination) was indicated by $30 \%$ of respondents (30\% of $3^{\text {rd }}$ year students, $14 \%$ of $4^{\text {th }}$ year students, $24 \%$ of $5^{\text {th }}$ year students, and the most, 50\%, of $6^{\text {th }}$ year students).

Responding to the question "what is the first test you will do to identify or exclude the pulmonary embolism?",

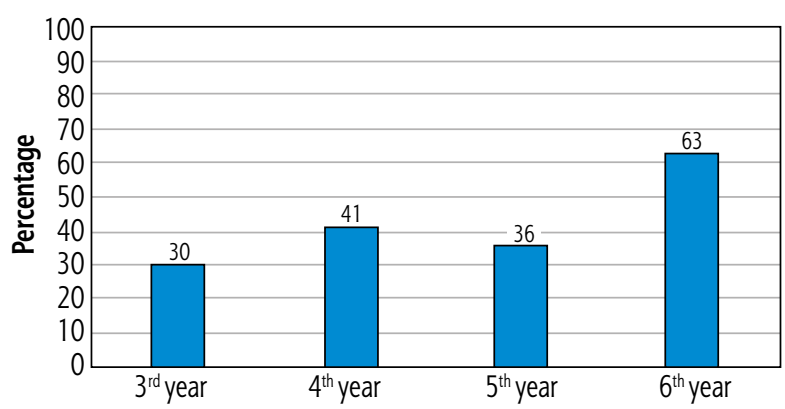

Fig. 3. Percentage of correct answers for incidence rate of DVT in the population

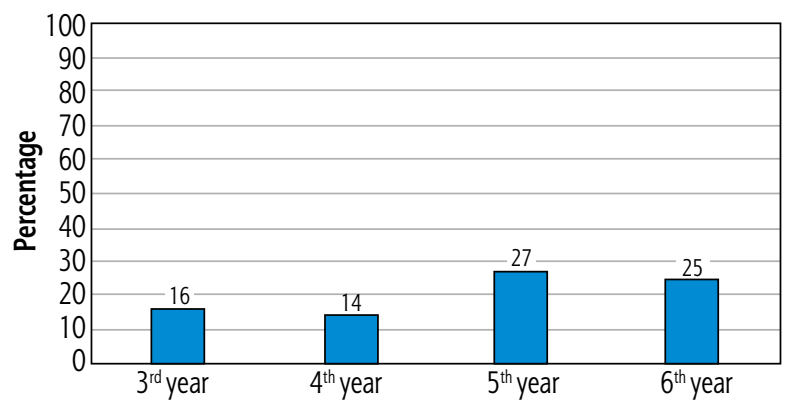

Fig. 4. Percentage of correct answers for risk factors of venous thromboembolism

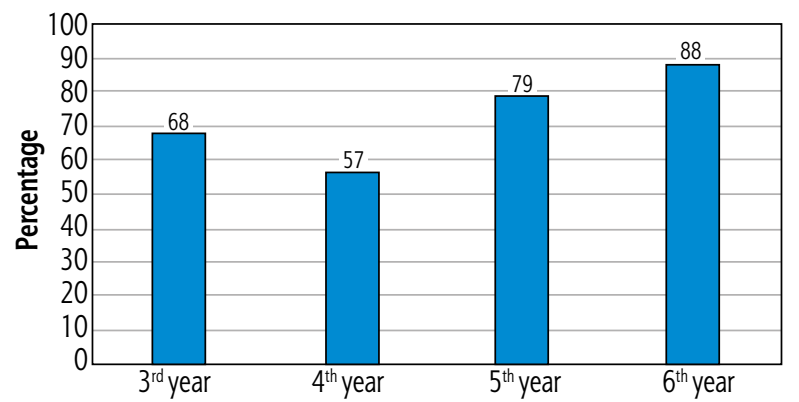

Fig. 5. Percentage of correct answers for first-choice diagnostic method in confirming/excluding PE (angio-CT)

$66 \%$ of students from the Medical University of Silesia indicated the correct answer, which was angio-CT, and $6^{\text {th }}$ year students got the best result (Fig. 5).

Asked about pharmacological treatment of deep vein thrombosis, antiplatelet drugs were indicated by $71.5 \%$ of the respondents (the most, $75 \%$, by $6^{\text {th }}$ year students, and the least, $67 \%$, by $3^{\text {rd }}$ year students). The rest of the interviewees stated that anticoagulation treatment should be used. In the question where the respondents were asked to select an inappropriate method of VTE prophylaxis (which was the use of acetylsalicylic acid for primary thromboprophylaxis), the correct answer was chosen by 
$29 \%$ of students only. The proposed VTE prophylaxis methods in this question included: early mobilization, graduated elastic stockings, intermittent pneumatic compression and anticoagulant use. Correct answers were indicated by $80 \%$ of $6^{\text {th }}$ year students, $55 \%$ of $5^{\text {th }}$ year students, $20 \%$ of $4^{\text {th }}$ year students and $17 \%$ of $3^{\text {rd }}$ year students. Concerning the question involving the problem of venous thromboembolism during long immobilization during long distance air flights, $35 \%$ of respondents were aware of the risk factors and that some methods of VTE prophylaxis should be implemented during long haul flights if needed (correct answers were stated by $40 \%$ of $3^{\text {rd }}$ year students, in $39 \%$ of $5^{\text {th }}$ year students and in $33 \%$ of $6^{\text {th }}$ year students).

Answering the question concerning the level of the current and obtained knowledge (information) about VTE on a scale from 1 to 10 , respondents stated it at the average level of 3.8 (4.09 in $3^{\text {rd }}$ year, 3.4 in $4^{\text {th }}, 4.7$ in $5^{\text {th }}$ and 3 in $6^{\text {th }}$ year students). Students of every clinical year stated that they were not taught enough about diagnosis and treatment of deep vein thrombosis. $76 \%$ of respondents claim that lecturers and classes during medical studies do not pay enough attention and devote insufficient time to deep vein thrombosis and pulmonary embo$\operatorname{lism}\left(60 \%\right.$ in $3^{\text {rd }}$ year, $64 \%$ in $4^{\text {th }}$ year, $83 \%$ in $5^{\text {th }}$ year and $83 \%$ in $6^{\text {th }}$ year students).

\section{DISCUSSION}

The lack of proper awareness concerning the disease as well as the lack of knowledge concerning the proper approach to VTE prophylaxis and treatment are definitively two important factors significantly related to the still very high mortality and morbidity rate in this group of patients [10]. Several other factors responsible for the poor clinical implementation of the proposed VTE prophylaxis and treatment guidelines are also identified including: physician-related factors (lack of familiarity with the guidelines, lack of agreement with the guidelines, lack of outcome expectancy, concerns about bleeding risk, difficulty of use of oral anticoagulation, lack of self-efficacy - inability to follow the guidelines), environmental factors (lack of time, lack of staff, poor reimbursement and increased practice costs, lack of reminder system) as well as guideline-related factors (confusing disagreement between the guidelines, guidelines are not easy or inconvenient to use, difficulties in adding new behaviour instead of changing an existing one, some of the guidelines are cumbersome) [11].

Taking into account the conditions mentioned above, the discrepancy between the guideline recommendations and the real world clinical approach to the problem of venous thromboembolism in the hospital as well as ambulatory settings is also potentially related to the proper health care provider education. In the study, both the questionnaire answers and student knowledge self-assessment suggest the need of medical high school education improvement in the VTE field. VTE-related subjects are part of the medical education and training at the medical faculty along the study course from the very early part of the clinical education. This subject is presented and discussed with students during the courses of physiology, pathology, pharmacology, internal medicine, surgery and vascular surgery.

In the performed study, we realized the lack of the proper students' knowledge concerning VTE symptomatology and pathogenesis in all the examined years of the medical faculty training, including in the $6^{\text {th }}$ (last) year students. Among 100 consecutive $6^{\text {th }}$ year students asked, $25 \%$ of the respondents could not specify Virchow's triad elements and only $25 \%$ of them knew the proper VTE definition (based on the presence of DVT and/or of PE). Several problems with the identification of VTE and DVT symptoms were also identified among the respondents the lack of knowledge concerning the often asymptomatic disease course as well as the limited understanding of the low specificity of potentially VTE-related symptoms should be especially emphasized. In this context the relatively low rate of correct answers to the question about proper DVT diagnostics in the symptomatic patient should be pointed out: only $29.5 \%$ of students identified ultrasound venous the compression test as well as venous duplex Doppler US as the screening diagnostic method in DVT patients $\left(30 \%\right.$ of $3^{\text {rd }}$ year, and $14 \%, 24 \%, 50 \%$ in years 4-6 respectively). Also in the PE field, the insufficient knowledge concerning angio-CT as the diagnostic method of choice to confirm the clinical suspicion should be mentioned (this method was indicated by $68 \%, 57 \%$, $79 \%$ and $88 \%$ of the students from the medical faculty, in the $3^{\text {rd }}, 4^{\text {th }}, 5^{\text {th }}$ and $6^{\text {th }}$ year respectively).

In the performed study, apart from the problems with the proper identification of the VTE risk factors, there are also problems related to the VTE prophylaxis rules. Only $29 \%$ of the students identified aspirin as the inappropriate way of pharmacological thromboprophylaxis. The proper methods of VTE prophylaxis were specified by $17 \%$ of students of the $3^{\text {rd }}$ year of the medical study, by $20 \%$ in the $4^{\text {th }}$ year and by $55 \%$ and $80 \%$ in the $5^{\text {th }}$ and $6^{\text {th }}$ year respectively. According to the presented results and students' self-assessment, in the programme of the medical faculty more attention should be paid to the education in the field of venous thromboembolism. This, in turn, can potentially improve and ensure safe and high quality medical care in the potential VTE patient population.

Continuous education in this field should be continued not only during the medical study but also afterwards and should concern all health care providers. In the VTE START study, based on a population of 258556 hospitalized patients, 68278 patients $(26.4 \%)$ were determined to be at risk of venous thromboembolism in various hospital departments. The rates of patients who received the appropriate type, dose, and duration of thromboprophy- 
laxis in critical care, medical and surgical patient wards were $10.5 \%, 9.8 \%$, and $17.9 \%$ respectively. Among the patients at risk, $36.8 \%$ received no thromboprophylaxis. The study publication was summarized with the conclusion concerning the need for physicians and health systems to improve awareness and implementation of recommended thromboprophylaxis [12].

According to the ENDORSE study based on a population of 68183 hospitalized patients in 32 countries, the proper VTE prophylaxis was used in $59 \%$ of the surgical patients at VTE risk and only in $40 \%$ of the medical patients at risk of VTE development (assessed according to risk factor presence) [13]. Tang et al. explored how the medical staff of intensive care units in China comprehend and practice VTE prophylaxis. In the questioned group of 1861 physicians and nurses, $36.5 \%$ of physicians and $22.2 \%$ of nurses were aware of the VTE guidelines, and $19.0 \%$ of physicians and $9.5 \%$ of nurses comprehended the latest ACCP Guideline edition ( $9^{\text {th }}$ Edition - 2012) $37.6 \%$ of the medical staff chose the VTE prophylaxis method based on the related guidelines [14].

One of the most significant problems related to the difficulties in the VTE prophylaxis and treatment guidelines implementation is the lack of proper VTE awareness among the medical staff. It concerns both risk factor evaluation with proper VTE risk stratification and diagnostic awareness in the potential DVT/PE patients. VTE can often be prevented, but in many cases the course of the disease can be potentially unpredictable, with very few clinical symptoms suggesting the disease occurrence [15-17]. Many VTE cases are still not diagnosed clinically and detected during the autopsy - this observation concerns especially the medical patient group but it can also happen in surgical patients at risk of VTE development [18]. The incidence of VTE increases during hospitalization as well as in the cases of coincidence of significant VTE risk factors [19].

The current VTE prophylaxis and treatment measures, including new medical therapies based on direct oral anticoagulants, significantly simplify both prophylaxis and treatment of this disease [20-23]. Despite the progress in the therapy, a significant proportion of VTE patients remain undiagnosed due to the asymptomatic or barely symptomatic disease course. This concerns both proximal and (especially) distal DVT as well as the number of PE cases. In term of the often asymptomatic VTE course, knowledge concerning risk factors as well as risk stratification has important value [24, 25].

Education as well as activities focusing on an increase of the awareness concerning venous thromboembolism can be addressed to the patient community, which seems to be much less informed about the disease risk consequences and symptoms. In a study published in 2017 by Almodaimegh et al. the Saudi Arabia in-hospital patients' awareness of VTE and their perceptions of thromboprophylaxis were evaluated. Among the 174 patients stud- ied, only $32 \%$ were familiar with the risk and possibility of DVT occurrence, while for PE the rate was even lower, $15 \%$. Only $5 \%$ of the patients with knowledge of DVT identified leg swelling as a potential DVT symptom [26].

In the general (non-hospital) population the knowledge and awareness of VTE also seems to be very low and significantly lower than the knowledge concerning other cardiovascular diseases such as stroke or heart infarction. In a study assessing the global public VTE awareness, 800 respondents from 9 countries were questioned [27]. The rates of respondents who were aware of thrombosis, DVT and PE were $68 \%, 44 \%$ and $54 \%$, and this was significantly lower than the proportion that were aware of other thrombotic disorders, such as heart attack and stroke ( $88 \%$ and $85 \%$ respectively). In the same study, the awareness of cancer, hospitalization and surgery as the risk factors turned out to be very low $(16 \%, 25 \%$ and $36 \%$ respectively) and only $45 \%$ of the respondents were aware that blood clots are preventable.

Looking for the possibility to improve this situation, in the AVTERS study, Tomkowski and co-workers focus on the efficacy of the public awareness campaign on the incidence of symptomatic objectively confirmed deep vein thrombosis [27]. In this controlled study a campaign to raise public awareness of DVT was performed during one year in an urban population of 100000 and compared with the control group in terms of the symptomatic DVT referrals and confirmations by general practitioners by compression ultrasound. The one year incidence of diagnosed DVT was 36/100 000 in the population that underwent education and 14/100 000 in the control (without the educative approach). Of course, for the wider implementation of such an approach, the significant costs should be taken into consideration. As this is probably not possible at this moment as a worldwide strategy, at least medical staff and all medical health care providers should be aware and sufficiently educated in the field of risk factor assessment, prophylaxis as well as diagnostics and treatment of DVT and/or PE. This education should remain an important part of the pre- and post-graduate training as well as part of the continuous education in most of the medical specialties.

The present study demonstrates the lack of sufficient awareness of VTE, DVT, and PE as well as the lack of sufficient knowledge concerning the pathogenesis, risk factors, and diagnostics among medical students, including the last year of medical faculty student group. Based on our study results, action towards an increase of medical high school students' awareness as well as action towards more practical education in this field in the medical faculty of the medical university should be proposed.

\section{CONCLUSIONS}

Although the study programme includes venous thromboembolism, the knowledge of students in the field 
of epidemiology, symptomatology and risk factors of this affliction is still limited. According to the results of the study, it is advisable to take action, including educative effort, which should lead to increased awareness of the future medical staff about problems related to VTE.

This research was supported by research grant no. KNW 1-185/N/6/K from Medical University of Silesia in Katowice.

The authors declare no conflict of interest.

\section{References}

1. Niżankowski R. Żylna choroba zakrzepowo-zatorowa. In: Interna Szczeklika, Gajewski P (ed.). Medycyna Praktyczna, Kraków 2016: 520-548.

2. Pesavento R, Lusiani L, Visonà A, Bonanome A, Zanco P, Perissinotto C, Pagnan A. Prevalence of clinically silent pulmonary embolism in deep venous thrombosis of the legs. Minerva Cardioangiol 1997; 45: 369-375.

3. Jha AK, Larizgoitia I, Audera-Lopez C, Prasopa-Plaisier N, Waters H, Bates DW. The global burden of unsafe medical care: analytic modeling of observational studies. BMJ Qual Saf 2013; 22: 809-815.

4. Anderson F. The prevalence of risk factors for venous thromboembolism among hospital patients. Arch Intern Med 1992; 152: 1660 .

5. Anderson FA Jr, Wheeler HB, Goldberg RJ, Hosmer DW, Patwardhan NA, Jovanovic B, Forcier A, Dalen JE. A population-based perspective of the hospital incidence and case-fatality rates of deep vein thrombosis and pulmonary embolism. The Worcester DVT Study. Arch Intern Med 1991; 151: 933-938.

6. Cohen AT, Agnelli G, Anderson FA, Arcelus JI, Bergqvist D, Brecht JG, Greer IA, Heit JA, Hutchinson JL, Kakkar AK, Mottier D, Oger E, Samama MM, Spannagl M; VTE Impact Assessment Group in Europe (VITAE). Venous thromboembolism (VTE) in Europe. Thromb Haemost 2007; 98: 756-764.

7. Tomkowski WZ, Dybowska M, Kuca P, Andziak P, Jawień A, Ziaja D, Małek G, Górska M, Davidson BL; AVTERS investigators. Effect of a public awareness campaign on the incidence of symptomatic objectively confirmed deep vein thrombosis: a controlled study. J Thromb Haemost 2012; 10: 2287-2290.

8. Raskob GE, Angchaisuksiri P, Blanco AN, Buller H, Gallus A, Hunt BJ, Hylek EM, Kakkar A, Konstantinides SV, McCumber M, Ozaki Y, Wendelboe A, Weitzand J, ISTH Steering Committee for World Thrombosis Day. Thrombosis. A major Contributor to Global Burden Disease. Arterioscler Thromb Vasc Biol 2014; 34: 2363-2371.

9. Wendelboe AM, McCumber M, Hylek EM, Buller H, Weitz JI, Raskob G, for the ISTH Steering Committee for World Thrombosis Day. Global public awareness of venous thromboembolism. J Thromb Haemost 2015; 13: 1365-1371.

10. Khorana AK. The NCCN Clinical Practice Guidelines on Venous Thromboembolic Disease: Strategies for Improving VTE Prophylaxis in Hospitalized Cancer Patients. Oncologist 2007; 12: 1361-1370.

11. Kakkar AK, Davidscon BL, Haas SK on behalf of the Investigators Against Thromboembolism (INATE) Group. Compliance with recommended prophylaxis for venous thromboembolism: improving the use and rate of uptake of clinical practice guidelines. J Thromb Haemost 2004; 2: 221-227.
12. Amin A, Spyropoulos C, Dobesh P, Shorr A, Hussein M, Mozaffari E, Benner JS. Are hospitals delivering appropriate VTE prevention? The venous thromboembolism study to assess the rate of thromboprophylaxis (VTE start). J Thromb Thrombolysis 2010; 29: 326-339.

13. Cohen AT, Tapson VF, Bergmann JF, Goldhaber SZ, Kakkar AK, Deslandes B, Huang W, Zayaruzny M, Emery L, Anderson FA Jr: ENDORSE Investigators. Venous thromboembolism risk and prophylaxis in the acute hospital care setting (ENDORSE study): a multinational cross-sectional study. Lancet 2008; 371: 387-394.

14. Tang X, Sun B, Yang Y, Tong Z. A Survey of the Knowledge of Venous Thromboembolism Prophylaxis among the Medical Staff of Intensive Care Units in North China. PloS ONE 2015; 10: e0139162.

15. Beckman MG, Hooper WC, Critchley SE, Ortel TL. Venous thromboembolism: a public health concern. Am J Prev Med 2010; 38 (4 Suppl): S495-501.

16. White RH. The epidemiology of venous thromboembolism. Circulation 2003; 107: I4-8.

17. ISTH Steering Committee for World Thrombosis Day. Thrombosis: a major contributor to the global disease burden. J Thromb Haemost 2014; 12: 1580-1590.

18. Lozano R, Naghavi M, Foreman K, Lim S, Shibuya K, Aboyans V, Abraham J, Adair T, Aggarwal R, Ahn SY, Alvarado M, Anderson HR, Anderson LM, Andrews KG, Atkinson C, Baddour LM, Barker-Collo S, Bartels DH, Bell ML, Benjamin EJ, et al. Global and regional mortality from 235 causes of death for 20 age groups in 1990 and 2010: a systematic analysis for the Global Burden of Disease Study 2010. Lancet 2012; 380: 20952128.

19. Vaitkus PT, Leizorovicz A, Cohen AT, Turpie AG, Olsson CG, Goldhaber SZ, Group PMTS. Mortality rates and risk factors for asymptomatic deep vein thrombosis in medical patients. Thromb Haemost 2005; 93: 76-79.

20. Kearon C, Akl EA, Ornelas J, Blaivas A, Jimenez D, Bounameaux H, Huisman M, King CS, Morris TA, Sood N, Stevens SM, Vintch JRE, Wells P, Woller SC, Moores L. Antithrombotic therapy for VTE disease: CHEST guideline and expert panel report. Chest 2016; 149: 315-352.

21. Schulman S, Kakkar AK, Goldhaber SZ, Schellong S, Eriksson H, Mismetti P, Christiansen AV, Friedman J, Le Maulf F, Peter N, Kearon C; RE-COVER II Trial Investigators. Treatment of acute venous thromboembolism with dabigatran or warfarin and pooled analysis. Circulation 2014; 129: 764-772.

22. Prins MH, Lensing AW, Bauersachs R, van Bellen B, Bounameaux H, Brighton TA, Cohen AT, Davidson BL, Decousus H, Raskob GE, et al. Oral rivaroxaban versus standard therapy for the treatment of symptomatic venous thromboembolism: a pooled analysis of the EINSTEIN-DVT and PE randomized studies. Thromb J 2013; 11: 21.

23. Agnelli G, Buller HR, Cohen A, Curto M, Gallus AS, Johnson M, Masiukiewicz U, Pak R, Thompson J, Raskob GE, Berkowitz SD, Wells PS; EINSTEIN Investigators. Oral apixaban for the treatment of acute venous thromboembolism. N Engl J Med 2013; 369: 799-808.

24. Zawilska K, Bała M, Błędowski P, Chmielewski DW, Dobrowolski Z, Frączek M, Frołow M, Gajewski P, Guzik T, Jaeschke R, Korman T, Kotarski J, Kozubski W, Krawczyk M, Kruszewski W, Kulikowski J, Kutaj-Wąsikowska H, Mayzner-Zawadzka E, Mrozikiewicz PM, Musiał J, Niżankowski R, Pasierski T, Poręba R, Tomkowski W, Torbicki A, Undas A, Urbanek T, Wojtu- 
kiewicz MZ, Woroń J, Wroński J. Polskie wytyczne profilaktyki i leczenia żylnej choroby zakrzepowo-zatorowej - aktualizacja 2012. Medycyna Praktyczna, Kraków 2012.

25. Tomkowski W, Kuca P, Urbanek T, Chmielewski D, Krasiński Z, Pruszczyk P, Windyga J, Oszkinis G, Jawień A, Burakowski J, Dybowska M, Kęsik J, Zubilewicz T. Żylna choroba zakrzepowo-zatorowa - wytyczne profilaktyki, diagnostyki i terapii Konsensus Polski 2017. Acta Angiol 2017; 23: 73-113.

26. Almodaimegh $\mathrm{H}$, Alfehaid L, Alsuhebany N, Bustami R, Raharbi S, Alkatheri A, Albekairy A. Awareness of venous thromboembolism and thromboprophylaxis among hospitalized patients: a cross-sectional study. Thromb J 2017; 15: 19.

27. Wendelboe AM, McCumber M, Hylek EM, Buller H, Weitz JI, Raskob G, for the ISTH Steering Committee for World Thrombosis Day. Global public awareness of venous thromboembolism. J Thromb Haemost 2015; 13: 1365-1371. 